\title{
Physical loss evaluation in water distribution systems in the metropolitan region of São Paulo, Brazil
}

\author{
A. R. S. Diniz \& J. G. Dalfré Filho \\ College of Civil Engineering, Architecture and Urbanism - UNICAMP, \\ Brazil
}

\begin{abstract}
This study proposes a method for the diagnosis of real water loss and for the actions which reduce this problem in water distribution systems. By adopting the parameters involved in the evaluation of real water loss, actions targeting combat and reduction of loss are prioritized, which allows for the optimization of the available resources. The topic of water loss reduction has recently been widely discussed, which is especially related to advances in information technology and to the availability of data within Brazilian water supply systems. The greater Sao Paulo area is one of the world's most populated areas, with 20 million inhabitants. The Water System Cantatereira of Sao Paulo is very important in this area, supplying water to $60 \%$ of the entire population. In this system, one of the most relevant distributors is the Casa Verde Sector, composed of 84.2 kilometers of water distribution networks, 11,002 connections, and 16,891 homes, all with a water flow of $201.9 \mathrm{l} / \mathrm{s}$. With the employment of geophones, listening stems and leak noise correlation, non-visible leaks were detected in this important and complex system, when water flow and pressure were recorded. All data was analyzed and correlated with information in the Geographic Information System (GIS). This study presents the results yielded by analyzes carried out with the software Water Audit 4. This software can be applied to any water supply system and is provided at no cost by the American Water Works Association (AWWA). It was concluded that the Casa Verde Sector must develop a specific strategy for water loss reduction, based on the renovation of the facilities and on the method of storage used for pressure data.
\end{abstract}

Keywords: water distribution networks, control of physical losses, leak detection, case study. 


\section{Introduction}

Research that aims at reducing water loss must be strengthened in order to investigate the potential bottlenecks of each specific sector, which can allow for improved system efficiency in the water supply. If Brazil is to keep up with the worldwide evolution that happens in the control of losses, and also with the challenges this matter presents, the national control of real water loss must be enlarged. The subject of water loss reduction has been widely discussed, especially in the present days, given that water scarcity is imminent, and any alternative that proposes an increase in water supply to the population needs to be evaluated. Moreover, financial losses caused by water loss in supply networks represent a barrier to the evolution of the very own systems. The moment seems appropriate for a deep analysis of the issue, mainly because of the advances in information technology and the compiling of data regarding water supply networks in Brazil.

According to Thornton et al. [1], loss of water revenue is defined as the total sum of the real losses (physical losses), the apparent losses (non-physical) and the authorized non-invoiced consumption. According to Kingdom et al. [2], the values of non-billed water worldwide is estimated at 48.6 billion $\mathrm{m}^{3} /$ year, and that the volume of real losses that occur in developing countries would be enough to supply water for 200 million people. The problem with water loss is especially related to the obstacles faced by the very own water network distribution company at a given place. Such companies do not have autonomy, are not considered liable and possess poor technical and managerial skills that are necessary to offer a reliable service to the population.

The present study offers an evaluation of the method known as Hydric Balance, with the intent to reduce losses related to non-visible leaks and pressure reduction in water supply networks. Results of this method were determined with a free computational model referred to as Water Audit 4, provided by the American Water Works Association (AWWA [3]).

\section{Literature review}

In Brazil, the governmental agency that is responsible for collecting data on loss of revenue in water distribution networks is the Ministry of Cities, through the National System of Sanitation Information (SNIS/PMSS [4]). In 2009, this Ministry announced that the national average on loss of revenue was $37.1 \%$, and Figure 1 shows the loss indexes by Regional Network Distributions.

In Figure 1, it is noted that a reduction in the revenue loss index is a challenge, being that there is a variation of approximately $60 \%$ when one compares the network distribution with the lowest and highest index.

The leaks' flow is exponentially related to pressure, as presented by Equation (1) (Lambert and Thornton [5]):

$$
Q_{1} / Q_{0}=\left(P_{1} / P_{0}\right)^{N_{1}}
$$




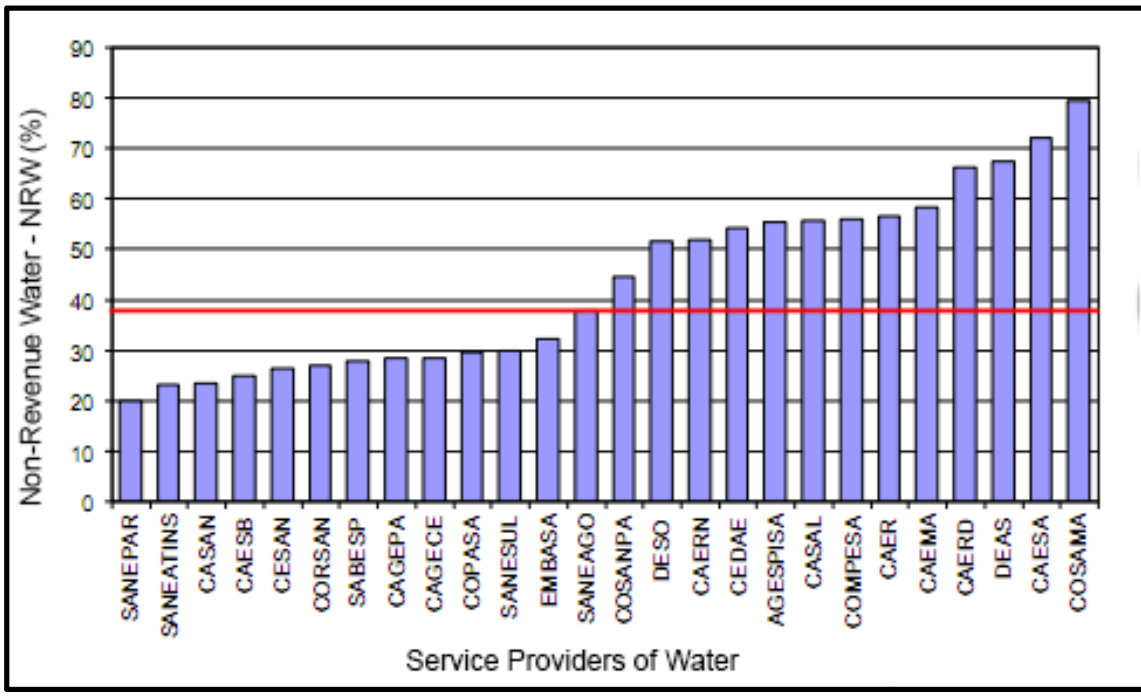

Figure 1: $\quad$ Mean index of revenue loss among NSSI participants (2009) [4].

where $\mathrm{Q}_{1}$ is the pressure leak flow $\mathrm{P}_{1}, \mathrm{Q}_{0}$ is the leak flow to the pressure $\mathrm{P}_{0}$ and $\mathrm{N}_{1}$ being an exponent. The exponent $\mathrm{N}_{1}$ can vary between 0.5 and 2.5, depending on the material the pipeline is made of. For metallic pipes, $\mathrm{N}_{1}=0.5$; for plastic tubes, $1.5<\mathrm{N}_{1}<2.5$; for inherent leaks, $\mathrm{N}_{1}=1.5$ (Lambert and Thornton [5]).

SABESP (State of Sao Paulo Basic Sanitation Agency) presents an innovative system whose interaction between the models SIGNOS and WATERCARD allows for a simultaneous spatial reading. SIGNOS is a model that utilizes the Geographic Information System (GIS), transferring the information of the technical and commercial registration to the hydraulic modeler WATERCARD. Then, with a higher processing speed, it is possible to graphically visualize technical, commercial and operational information, allowing the company to establish action plans and to direct investments in an assertive manner. Results expected from this process are maintenance cost reduction, decrease of loss through leak concentration, facility renovation and an overall improvement in the services provided.

In Fantozzi et al. [6], it is possible to observe the logic forms of the equations relative to real losses (RL) as a function of the network length $\left(\mathrm{L}_{\mathrm{m}}\right)$ and the number of connections $\left(\mathrm{N}_{\mathrm{s}}\right)$, as presented by Equation (2) and Equation (3):

$$
\begin{gathered}
R L_{(L / \text { dia })}=\left(A+B \times L_{m} \times N_{s}\right) \times P \\
R L_{(L / k m \text { de rede/dia })}=\left(A+B \times N_{s} / L_{m}\right) \times P \\
R L_{(L / \text { ligação/dia })}=\left(A \times L_{m} / N_{s}+B\right) \times P
\end{gathered}
$$


where A and B are network coefficients, $N_{s} / L_{m}$ is the connections' density per kilometer of network, and $\mathrm{P}$ is the pressure. The coefficient values $\mathrm{A}$ and $\mathrm{B}$ can be obtained through linear regression of data from utilized systems, using either Equation (3) or (4), or from the use of component models such as BABE, Background and Bursts Estimates.

AWWA [3] presents the hydraulic loss modeler, made available through AWWA's website and named Water Audit 4. Water Audit 4 provides the user with the necessary adjustments for the estimation of lost volumes, ranging from the simplest systems to those which make use of measuring equipment that employs state-of-the-art technologies. Therefore, this model balances the imprecision levels in flow measurement, and estimates the volume of inherent leaks, based on the characteristics of the system in question. Seeking to avoid mistakes in the use of this tool, Water Audit 4 offers alert signals when input information presents divergence in what refers to the volume portions that compose the water loss audit. The software offers the ability to obtain attributes for multiple system configurations.

Melato [7] suggests that water audits are performed through loss techniques that are internationally employed and recognized. Water audits identify the losses and the cost of volume loss and provide this important information to distribution network companies. The goal of the audit is to support and educate the distribution network company, through the provision of data and results from measurement and control systems, in the selection and implementation of programs aimed at reducing losses in the water supply system. According to Melato [7], two methods can be employed to comprehensively evaluate losses: Top-down, known as Hydric or Water Balance and bottom-up, known as evaluation of the nightly minimum flow. In addition to these two methods, there is the BABE method which analyses components of real loss. The following referred methods are presented below.

SABESP [8] asserts that, since the 1970s, in order to meet the Project Norms from ABNT (Brazilian Association of Technical Norms) dealing with limits of superior pressure, especially in regions with irregular topography and low relative densification, stand-pipes and pressure-breaking boxes were installed in pressure micro-zones. Such solutions had relatively high costs, and were subject to failure due to technological limitations of the very own pressure-breaking devices. With urban expansion moving to the suburbs, and the search for an alternative, more economical solution, pressure-reducing valves (PRV's) started to be considered for an adequate solution for the process. PRV's are also used as pressure controls.

They can be configured in many other ways and have various applications, including; pressure-sustaining, pressure-relief, flow regulating, pump control valves and also as valves of protection against hydraulic transients. Depending on the needs of the supply system, they can also have combined functions, such as pressure-sustaining valve regulation and pressure-sustaining valve relief. 


\section{Experimental facility}

For the study of control of real losses, $84.2 \mathrm{~km}$ of treated water supply networks from the Casa Verde Sector were used. Such treated water supply networks belong to the Cantareira producer in São Paulo, as seen in Figure 2.

The Casa Verde Sector is composed of 11,002 connections and 16,891 homes, and has a flow of $201.9 \mathrm{l} / \mathrm{s}$. Moreover, it is worth noting that $75 \%$ of the components of the supply systems were installed prior to the year 1970 .

In this scenario, using the hydraulic balance method, the non-visible leaks were detected through the technique that employs geophones, listening stems, leak noise correlation. Also, the flow and pressure readings were recorded with the use of piezometers and data loggers. All data was analyzed and correlated with the information from the Geographic Information System (GIS).

In sequence, the data was added to the historic of the non-visible leaks, and were used to assist in the control of real losses. Next, parameters of leak and flow quantities were analyzed, such that indicators that contributed to the evolution of the real loss control in water supply networks were obtained.

São Paulo Metropolitan Region (RMSP)

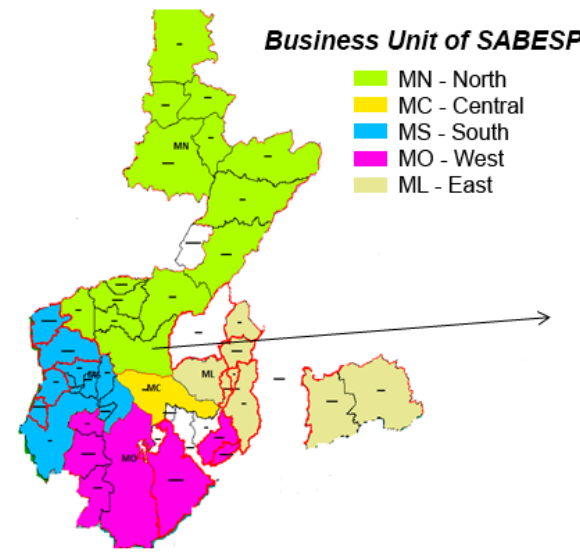

Casa Verde Sector (MN)

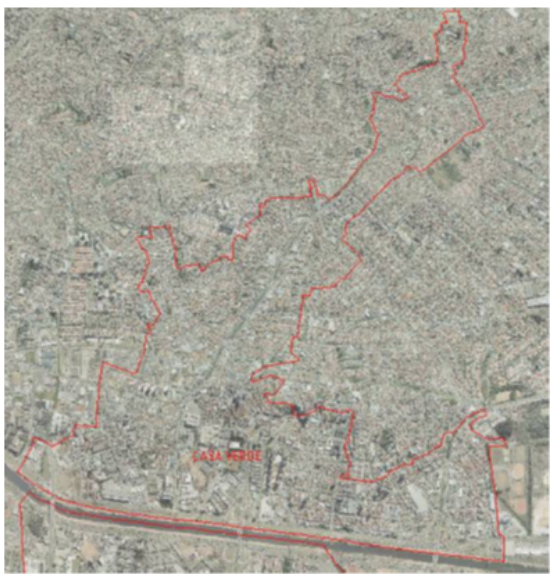

Figure 2: SPGA and Sector Casa Verde in Sao Paulo. Source: SABESP (2010).

The criteria applied in the choice of the area for the study were determined by the records of studies made in the Northern Business Unity of SABESP (MN), which has been seeking continued improvement for years. Additionally, the area has been seeking ways to challenge the rationalization of certain processes, reduce water loss, increase business revenue and decipher the improvement opportunity that is present in a facility which has water networks that have been utilized for more than 40 years, being installed prior to 1970 . 


\subsection{Casa Verde sector parameter description}

The Casa Verde Sector is configured by a single piezometric sector with an altitude variation between $755.00 \mathrm{~m}$ and $720.00 \mathrm{~m}$. Spread through an area of $466.30 \mathrm{ha}$, the area is a well-defined demarcation, according to SABESP. It is supplied by the Casa Verde Sector, which has a total capacity of $12,000 \mathrm{~m}^{3}$, and a maximum operational water level of $774.23 \mathrm{~m}$, causing the range of operational pressure of the Sector to vary from a maximum static pressure of $54.23 \mathrm{~m}$ to a minimum of $19.30 \mathrm{~m}$.

Currently, the measurement of the water that arrives at the Casa Verde reservoir is taken at a spot in the $600 \mathrm{~mm}$ adductor. Because the Sector has a single pressure zone, there is the need to measure only the water that passes from Casa Verde (MN), which is the focus of this study, to Casa Verde (MC), which is not included in this study. The macro meter is located upstream of the $600 \mathrm{~mm}$ water meter present on the Limão Bridge, on Ordem e Progesso Avenue.

In Table 1, the sector's mean flow defined by SABESP [9] originated from the application of the coefficients $\mathrm{K}_{1}=1.2$ and $\mathrm{K}_{2}=1.5$.

Table 1: $\quad$ Flows, sector Casa Verde.

\begin{tabular}{|c|c|c|c|}
\hline Year Flow & $\begin{array}{c}\text { Mean daily } Q \\
(\mathrm{l} / \mathrm{s})\end{array}$ & $\begin{array}{c}\text { Maximum Daily } Q \\
(\mathrm{l} / \mathrm{s})\end{array}$ & $\begin{array}{c}\text { Maximum } \\
\text { Hourly } Q \\
(\mathrm{l} / \mathrm{s})\end{array}$ \\
\hline 1997 & 90.00 & 108.00 & 162.00 \\
\hline 1998 & 88.20 & 105.84 & 158.76 \\
\hline 2007 & 87.12 & 104.55 & 156.82 \\
\hline 2017 & 94.93 & 113.92 & 170.88 \\
\hline
\end{tabular}

Source: SABESP (2010).

\subsection{Active leak control}

Active leak control is associated with flow monitoring. When an anomaly is verified, network and building extension inspection begin, analyzing the entire network with piezometric measuring equipment "in loco".

After finding the possibility of charge loss due to potential leaks, a leakage search begins with electronic geophones that amplify signs that characterize leaks through the propagation of sound waves in pressurized water networks that vary between $30 \mathrm{~Hz}$ and 3,000 $\mathrm{Hz}$ in the majority of cases.

After the approximate location of the leak is identified, the geophone device is employed. In cases when it is impossible to exactly determine the location of the leak, the analysis is improved with the use of a leak noise correlation. This device is composed of two or three sensors that capture leakage noise and send the signal through radiofrequency to a processor that locates the leakage spot by determining the time delay of the signal transmission. 


\subsection{Hydric balance method application}

The estimation of loss in a water supply system is given by the comparison between the water volumes transferred from an area in the system to the water volume received at one or more areas in the supply system, with areas located in points of influence relative to the transfer point.

The identification and separation of real and apparent water loss is made technically possible through field research employing a consumption histogram analysis method, also known as continuous records, with verification of pressure and flow accomplished with micro and macro meters. In this case, the nightly supply stabilized during the night, deducting continuous nightly consumption from service users such as manufacturers and hospitals. This is commonly represented by the real loss in a specific period of time, which is due to leaks in networks or building connections. The apparent loss will then be the difference between the total water loss in the distribution, the non-accounted water, consumed through fraud and illegal connections, and the verified real loss.

When the distribution network is evaluated, the largest leak indexes are present in building connections, which does not mean higher volume loss, so the entire sector must be investigated.

In order to find the performance indicator, the comparative value between periods was employed with the hydric balance method, using measurements retrieved "in loco". The variable which was indirectly measured, the flow between the entrance and the exit of the system, shows a tendency of increasing or decreasing the flow and the pipeline pressure in the supply system. Instant consumption constitutes the flow indicator, and such control allows for the easy detection of new losses in systems and sub-systems, in a timely and reliable manner. Daily consumption obtained from this information allows, in turn, for information on how to adjust the distribution networks according to the current regional consumption and consumption tendencies. The monthly consumption, on the other hand, is represented by the variable measured at residence meters divided by the difference between two consecutive readings. This way, it is possible to compare with the individual consumption of each residence and make deductions. The installation of measurement and control districts with the use of pressure-reduction valves and non-visible leaks-detection valves has been excelling, due to the quick return in investments. Additionally, the use of the values has become increasingly popular due to the fact that many reasons lead a water distribution system, or part of it, to operate with pressure that exceeds the operating pressure for specific service levels which are considered adequate by the respective clients.

\section{Results and analysis}

From field research, a quantification of leaks was extracted, as shown by Tables 2 and 3 that present various variables, including; sector, date, length of investigated networks, number of leaks in networks, number of leaks in connections, index of leaks found per kilometer in the studied networks, and the 
research index - which is the percentage mean in relation to the total extension of the supply networks of the supply system that must be correlated with the recovered water volume.

In order to help control losses and make the parameter readings practical, the model was used in accordance with Diniz [10], presenting the monitoring history of the daily mean flows during the experimental period, where the method is proposed and results are compared to previous periods. Finally, potential deviations are presented, in relation to the goals set during the planning phase and the actions observed to minimize physical losses in the water supply sector Casa Verde (MN).

Table 2: $\quad$ Monthly indicators of research in non-visible leaks.

\begin{tabular}{|l|c|c|c|c|c|c|}
\hline Sector & Date & $\begin{array}{c}\text { NL } \\
(\mathrm{m})\end{array}$ & $\begin{array}{c}\text { NeL } \\
(\mathrm{un})\end{array}$ & $\begin{array}{c}\text { CoL } \\
(\mathrm{un})\end{array}$ & $\begin{array}{c}\mathrm{I} \\
(\mathrm{Q} / \mathrm{km})\end{array}$ & $\begin{array}{c}\text { MI } \\
(\%)\end{array}$ \\
\hline Casa Verde & $01 / 2009$ & 29,390 & 0 & 44 & 1.50 & 8.44 \\
\hline Casa Verde & $02 / 2009$ & - & - & - & - & $-*$ \\
\hline Casa Verde & $03 / 2009$ & 44,630 & 0 & 47 & 1.05 & 53.40 \\
\hline Casa Verde & $04 / 2009$ & 51,340 & 2 & 37 & 0.76 & 58.97 \\
\hline Casa Verde & $05 / 2009$ & - & - & - & - & $-*$ \\
\hline Casa Verde & $06 / 2009$ & 22,210 & 3 & 34 & 1.67 & 26.59 \\
\hline Casa Verde & $07 / 2009$ & - & - & - & - & $-*$ \\
\hline Casa Verde & $08 / 2009$ & 39,205 & 12 & 55 & 1.71 & 46.84 \\
\hline Casa Verde & $09 / 2009$ & 67,804 & 7 & 42 & 0.72 & 81.00 \\
\hline Casa Verde & $10 / 2009$ & 11,640 & 2 & 14 & 1.37 & 13.86 \\
\hline Casa Verde & $11 / 2009$ & 36,540 & 0 & 46 & 1.26 & 43.51 \\
\hline Casa Verde & $12 / 2009$ & - & - & - & - & $-*$ \\
\hline
\end{tabular}

Legend: NL - Length of the Researched Network; NeL - Leaks in Networks; CoL Leaks in Connections; I - Flow Index per Kilometer; MI - Research Mean Index;

*Period during which measurement was not possible due to system complexity.

Table 3: $\quad$ Annual indicators of research in non-visible leaks.

\begin{tabular}{|l|c|c|c|c|c|c|}
\hline \multicolumn{1}{|c|}{ Sector } & Date & $\begin{array}{c}\text { NL } \\
(\mathrm{m})\end{array}$ & $\begin{array}{c}\text { NeL } \\
\text { (un) }\end{array}$ & $\begin{array}{c}\text { CoL } \\
\text { (un) }\end{array}$ & $\begin{array}{c}\text { I } \\
(\mathrm{Q} / \mathrm{km})\end{array}$ & $\begin{array}{c}\text { MI } \\
(\%)\end{array}$ \\
\hline Casa Verde & $01 / 2009$ & 200,442 & 31 & 171 & 1.01 & 15.16 \\
\hline Casa Verde & $02 / 2009$ & 197,502 & 28 & 170 & 1.00 & 14.98 \\
\hline Casa Verde & $03 / 2009$ & 242,132 & 28 & 217 & 1.01 & 18.42 \\
\hline Casa Verde & $04 / 2009$ & 286,802 & 29 & 251 & 0.98 & 21.82 \\
\hline Casa Verde & $05 / 2009$ & 286,802 & 29 & 251 & 0.98 & 21.88 \\
\hline Casa Verde & $06 / 2009$ & 309,012 & 32 & 285 & 1.03 & 23.64 \\
\hline Casa Verde & $07 / 2009$ & 274,791 & 20 & 259 & 1.02 & 21.07 \\
\hline Casa Verde & $08 / 2009$ & 252,879 & 29 & 258 & 1.13 & 19.50 \\
\hline Casa Verde & $09 / 2009$ & 254,579 & 24 & 259 & 1.11 & 19.68 \\
\hline Casa Verde & $10 / 2009$ & 266,219 & 26 & 273 & 1.12 & 20.70 \\
\hline Casa Verde & $11 / 2009$ & 302,759 & 26 & 319 & 1.14 & 23.67 \\
\hline Casa Verde & $12 / 2009$ & 302,759 & 26 & 319 & 1.14 & 23.80 \\
\hline
\end{tabular}

Legend: NL - Length of the Researched Network; NeL - Leaks in Networks; CoL Leaks in Connections; I - Flow Index per Kilometer; MI - Research Mean Index. 


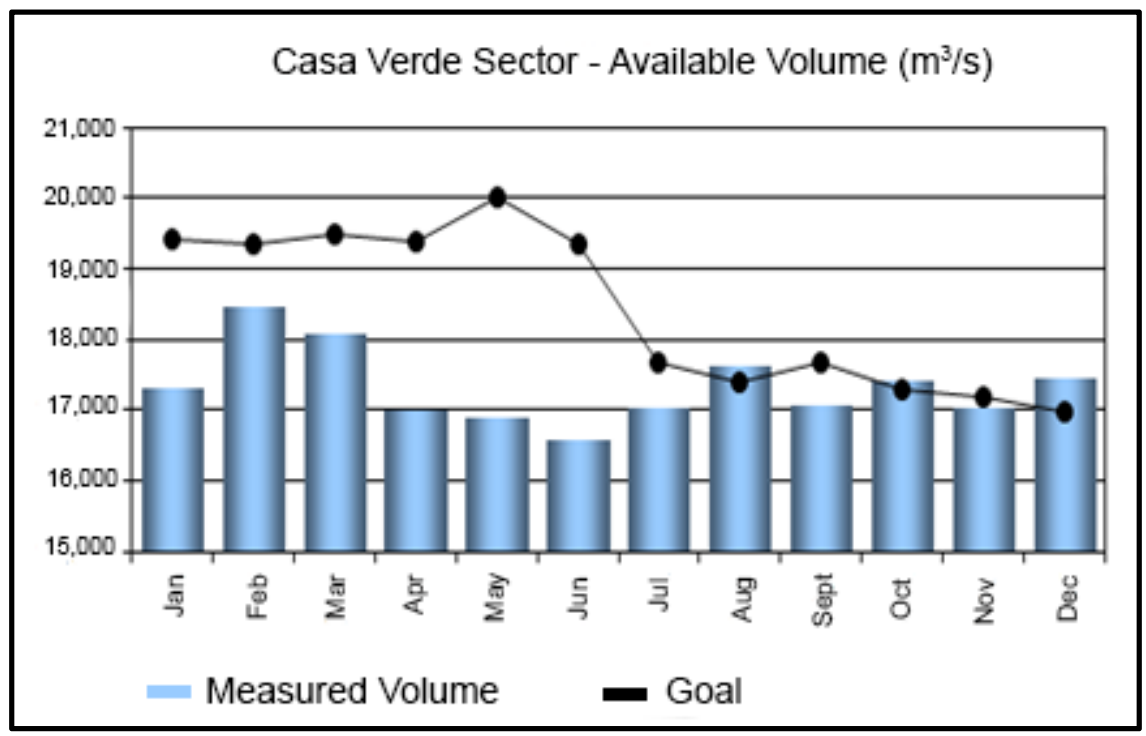

Figure 3: $\quad$ Daily flow means for casa Verde sector in 2008 and 2009.

The improvement of real loss control measures in water supply networks demonstrated that it is possible to recover a specific water volume loss, when compared to volumes presented in Table 3, which represent the hydric balance of the Casa Verde Supply Sector (MN) in its annual evolution. Therefore, a reduction in the order of $800,000 \mathrm{~m}^{3}$ per year in the volume directed to the accounting of losses was assessed, when observing the column of real losses in December of 2009 in relation to the last 12 months. This amount would allow for water to be supplied to 40,000 clients during approximately 35 days.

\section{Conclusion}

The analyses of the recovered volumes indicate that performing hydric balance with the hydric model of losses in the software "Water Audit v.4" (AWWA, [11]) is an efficient supporting technique in water loss control. Due to the fact that a software user needs varied types of data, one needs to know the system so they can obtain results from different practical application scenarios, which contributes to an assertive application of investments in the control of real losses.

The study results also point out that building connections are the major source of water waste in supply networks. Thus, it is necessary to emphasize that research on installation techniques or on more resistant materials is indeed needed, not only in initial installation but also during maintenance periods.

One of the potential follow up studies could be the replacement of supply networks and building connections with a technologically-enhance material, in an effective control area with data on maintenance records and loss indicators. This way, it would be possible to compare it to conventional actions designated 
to reducing loss control in supply systems. In this context, mathematical models of simulation-optimization employed to locate leakages, based on the inverse method, would fit as an excellent tool in efforts to investigate leaks "in loco". Such research would considerably reduce the length of networks to be studied using detection devices, being geophones, data loggers, or noise correlations.

Given the potential gains of return and the scarcity of this precious resource, it is recommended that investments in this sector be increased. Continued research in the analyses of the model under the transitory flow regimen, seeking to improve the propagation range of waves that are typical of leakages and the factors that cause recurrence of network and building ruptures, is a necessary future step. Such continued research will better ensure that water volumes that are now characterized as inherent losses can be identified with the help of innovative technologies.

\section{Acknowledgements}

The authors would like to acknowledge SABESP (Companhia de Saneamento Básico do Estado de São Paulo) for the data availability, MSc. Ricardo da Silva Manca for the discussions and Benjamin Williams for the English reviewing.

\section{References}

[1] Thornton, J.; Sturm, R.; Kunkel, G. Water Loss Control. $2^{\text {nd }}$ ed. EUA. McGraw-Hill. 2008. p. 345-350.

[2] Liemberger. R.; Marin P.; Water supply and sanitation board discussion paper series. Paper n. 08 The World Bank, Washington, DC. 2006. P 52.

[3] American Water Works Association (AWWA). In: XX Water Loss Conference, 2010, São Paulo, Annals. p.1080.

[4] SNIS /PMSS - Diagnostics of water and sewage services 2009. Ministry of Cities. National secretary of environmental sanitation, Brazil.

[5] Lambert, A.; Thornton, J. Evaluation of real losses. São Paulo Region. SABESP, 2002. p.132.

[6] Fantozzi, M. et al. Some examples of European water loss targets, and the law of unintended Consequences, Water Loss, São Paulo, 2010. p.192.

[7] Melato, D. S.. Discussion of a methodology for the diagnostics of and actions to reduce water loss: application in the water supply system of the São Paulo Great Area. Thesis (Master's in Civil Engineering). University of São Paulo’s “Escola Politécnica”, São Paulo, 2010.

[8] Sabesp. Signos-geographic information system in sanitation. Available at: http://www.premiomariocovas.sp.gov.br/pesquisa2005/tic\%20transacoes\% 20internas/tt_274.doc. Accessed on: March 22 ${ }^{\text {nd }}$, 2006.

[9] Sabesp. Companhia de saneamento básico do estado de São Paulo (Agency of basic sanitation of the State of São Paulo). Management of water loss. Department of integrated planning "MPI" - 2005. p.44. at:<http://www.cidades.gov.br/index.php?option=com_content\&view=artic 
le\&id=405:indicadores\&catid=90\&itemid=119. $>$ Accessed on: Aug $18^{\text {th }}$ 2011.

[10] Diniz, A.R.. Evaluation of physical loss control in water distribution systems of the São Paulo Metropolitan Region. Thesis (Master’s in Civil Engineering). University of Campinas, Campinas, 2012.

[11] American water Works association (AWWA). Water Audit 4 - AWWA Water Loss Control Committee Water Audit Software Compiler v4.2.9 (2011). Available at: <http://www.awwa.org/resources-tools/waterknowledge/water-loss-control.aspx>. 